\title{
Roles of Buddhist Monks in Moral Development following Sufficiency Economy Philosophy
}

\author{
Phrakhru Thamrongwongvisut (Theerasak Phuangpool) ${ }^{1}$, Phra Sithisinghasani (Sophon Sophano) ${ }^{2}$, \\ Phrakhru Wichitpathumrat $^{3}$, Lampong Klomkul ${ }^{4}$ \\ ${ }^{1,2,3,4}$ Faculty of Education, Mahachulalongkornrajavidyalaya University, Thailand \\ ${ }^{1}$ mcuthomrong@gmail.com, ${ }^{4}$ research.mcu@gmail.com
}

\begin{abstract}
The purpose of this article was to propose a model of moral and ethical development according to the philosophy of sufficiency economy. Documentary study was used by studying the role of Buddhist monks and analyzing the consistency of morality, ethics, and philosophy of sufficiency economy consisted of modesty, rationality, and immunity that based on the conditions of knowledge and morality. Results indicated that the guidelines for moral development began with the development of education in order to provide people with knowledge with various abilities, and also apply the aforementioned knowledge to occupations building well-being for yourself and your family. For moral and ethical development, it is very important aspect for social development. Considering with the current situation in Thai society, it can be seen that the chaos of Thai society today is mainly due to the lack of moral and ethical lifestyle. Therefore, moral and ethical development must know how to improve oneself to be people with sufficient knowledge, and be a person who spends sufficiently on education, a person with good physical health and mental health, and be a learner who know how to solve problems, and know how to think reasonably. There are five aspects in a model of moral and ethical development consisted of education, Dhamma propagation, social welfare, inherit culture, promote and preserve environment. There are two important principles for the maximum benefit which are virtues for a good household life, and virtues conducive to growth in wisdom.
\end{abstract}

Keywords

Buddhist Monks, Moral Development, Sufficiency Economy Philosophy

Article Received: 10 August 2020, Revised: 25 October 2020, Accepted: 18 November 2020

\section{Introduction}

At present, the monks play a role in human resource development in the community by integrating the principles of Dhamma into their application. It is about conducting economic activities by applying the principles of the way of life to live sufficiently according to the philosophy of sufficiency economy, which consists of modesty, rationality, and immunity to be able to produce or consume well, both in behavior morality and wisdom bring the community out of poverty, debt problems, and sufficiency, do not persecute oneself and others more importantly, it can take the mental development to the next level from the implementation of adequate economic activities, as help sharing unity and good relationship with people in the community. According to Buddhist principles that emphasize the production without self-persecution and others (honesty), consumption that focuses on moderation in order to keep the subject matter (nutrition), income distribution focused on helping the less fortunate (alms), the doctrine of the Lord Buddha, transmitted by the monks, emphasizes the development of the mind as already the original capital. It affects mental health and is an important variable for physical and mental health. The main role that monks have to perform in order to achieve their highest goals, another role is to help society and community. Since the monks have a way of life that has to rely on living with the householder by offering alms to sustain their lives, therefore, having relationship with the householder in that community. Monks have a duty to help society and community, so that people in society shun the people able to enhance the quality of physical, mental and intellectual behavior.

\section{The Role Of Monks In Moral And Ethical Devlopment}

The monks play a role for society by using social problems as a guide, activities that do partly respond to problems and have to look at the problem, be separated and narrowed. Some monks provide community-based social services, although the local problems are small but powerful and do not separate the problems that are related to each other, and more importantly, looking at the problems from a perspective independent of the capitalism, materialism and consumerism of the monks by tradition, the monks do not just teach theology. If there is still a secular role, such as teaching a profession to dig a pond, build a bridge and be a mediator to settle conflicts in the village, etc. The temple is therefore not a place to teach morals and rituals. The role of the monks in community development through the creation of public interests which is to create a bond and support the villagers with necessary things for the life of the community, for example, helping to build schools, build roads, community hall, more fair by cultivating morality. Morals, ethics and values are good for the people from one generation to another for a long time and also a religious succession. Monks have always been helping Thai society, especially in the countryside. By acting to help society and greatly lighten the burden of service of the society, it helps to strengthen the mind and character of the society, provide services according to the needs of the people relating to activities and religious rituals and influencing, motivating, or suggesting social activities and causing changes roles of moral and ethical development in village development. As a result, the village's problems began to resolve, such as 
higher income, reduced drugs, unity, additional occupation, group work, soil, water, forest, community and animals as a food source for villagers, families reduce the schism, good physical health arises and generosity towards one another, having a welfare fund reduce the cost of treatment and there are more personnel working as follows:

1. Role as the founder of the community activity group. and network organization groups.

2. Role as a consultant for enhancing and extending activities that are strong and sustainable for villagers in the community and network organizations.

3. Role as educator understanding of service management, community activities, and networking organizations

4. Role as a coordinator harmonize your thoughts coordinate for public and private agencies to support and strengthen the field of knowledge, materials, equipment and budgets to strengthen the organization in the community.

5. Role as community activity group facilitator and the network organization group has entered the place providing community information materials, equipment and services.

6. Role as a supporter and promoter to support group activities in the community and network organizations that carry out local activities as well as initial investment budgets facilitate the facility support in the provision of resources and other factors contributing to operations [1].

\section{Philosophy Of Sufficiency Economy}

Developing the country towards modernization has caused tremendous changes to Thai society in all aspects be it economic, political, cultural, social and environmental aspects. In addition, the process of change is so complex that it is difficult to explain in cause and effect because all changes are interconnected factors. Positive developments include an increase in the rate of economic growth. Material prosperity, various utilities, modern communication system, expanding the quantity and distribution of education more thoroughly but most of these positive effects spread to rural people, or the less disadvantaged in society, but the process of social change has followed negative consequences [2].

Sufficiency in life which is a basic condition that enables Thai people to be self-reliant and can lead a life with dignity under the power and freedom in determination own destiny. The ability to control and manage in order for oneself to be responsive to various needs, including the ability to manage problems on their own, all of which are considered fundamental potentials that Thai people and Thai society have previously had, must be impacted the economic crisis from the bubble problem and the vulnerability of the countryside as well as other problems that arise, all of which are proof and confirmation of this phenomenon as well.

Sufficiency economy is a philosophy pointing to the way of life and behavior of people at all levels from the family level, community level, to the state level in both the development and administration of the country to proceed in the middle way especially economic development to keep pace with the globalized world, sufficiency means modesty, rationality, and the need to have a reasonably healthy immune system against any impact caused by changes both inside and outside, this requires knowledge, prudence and great care in bringing various academic used in planning and execution of every step and at the same time must strengthen the mental foundation of the people of the nation especially government officials, theorists and businessmen at all levels to have a sense of virtue honesty and the right knowledge, living with patience, perseverance, wisdom and prudence, providing balance and readiness to support rapid and extensive changes both objects, society, environment and culture from the outside world as well.

The meaning of sufficiency economy consists of the following features [3]:

1. Modesty refers to the fit that is neither too small nor too much without hurting themselves and others, such as production and consumption at a modest level.

2. Rationality means a decision about the level of sufficiency must be logically based on relevant factors as well as taking into account the expected consequences of such actions.

3. Immunity means preparing to be ready to be affected and to change various areas to happen taking into account the possibility of various situations expected to happen in the future with the conditions of making decisions and performing various activities to be in the sufficiency level for 2 things as follows:

1. Knowledge conditions consisted of knowledge about various academic subjects related all around the prudence to put that knowledge into account for planning and caution in practice.

2. Moral conditions that must be strengthened and have an awareness of morality, honesty, patience, perseverance, and use of wisdom in life.

Sufficiency economy focus on manufacturers, consumers try to start production, consumed under the scope income limitation or existing resources, which is the key to reducing dependence increase the ability to control production by yourself and reduce the risk of not being able to control the market system effectively. Sufficiency economy does not mean being unreasonable, but may be luxurious from time to time, conventionally but most of the country often overspend beyond the position that can be obtained can lead to the goal of establishing economic stability, for example, basically Thailand is an agricultural country, the national economy should focus on the agricultural economy. Emphasis on food security creates stability as an economic system to a certain extent. It is an economic system that reduces risks. Economic instability in the long run can be applied at all levels, all branches, all sectors of the economy. It doesn't have to be limited to only agriculture or rural sectors, even the financial sector, real estate sector and international investment trade with a similar principle: emphasize discrimination in moderation, rationale, and immunity to oneself and society.

\section{Role Of Monk In Moral Development And Ethics According To Sufficiency Economy Philosophy}

Monks are considered the spiritual center of Buddhists. Buddhist life is tied to monks in one way or another. Therefore, the relationship between Buddhists in society and monks therefore cannot be separated. This is reason how they have to rely on each other all the time. The monks have roles in various fields to support the community as follows: [4] 


\section{The role of monks in education}

Since the past, the temple and the palace have always cooperated to educate people until education new plans in the reign of King Rama V, temples and clergy continue to cooperate in the administration of the nation's education especially at the elementary and primary levels later in the reign of King Rama VI, the study of measurement systems with the study of the new system to be completely separated direct educational duties of the monks, therefore, limited to temples and people in a narrow circle only from the importance of temples and Buddhism in the past evoke tradition is important that Buddhism is involved in education until the present day [5].

1. Temple traditions as a center for community education and the monks are the teachers who train and teach the townspeople and townspeople today may not be able to see it, but for the villagers in the remote countryside, still enough to see although not as central as before it is enough as a channel or a last resort.

2. Ordination tradition which means that ordination and study after the ordination, they must study or become a monk to study.

At present, the role of monks in education can be categorized as follows:

1. Early Child Training Center

2. Sunday Buddhism School

3. Dharma Education

4.Teachers teach morality in schools or Phra Dhammavidyakorn Education of the Buddha

6. Education management in Buddhist universities.

\section{The role of the monks in the teaching of Dharma}

In the past, the mission of monks was limited to temples and villagers according to traditions and occasions, such as preaching and teaching villagers on Buddhist monks or religious days, preaching in merit-making, ceremonies, or religious ceremonies such as making merit, house, funeral, etc. At present, communication is more convenient and faster the monks are able to carry out a wide variety of Buddhism and reach more people in different groups. The role of the monks in the dissemination of Dharma can be divided into 3 main things which are:

1. Phra Dhammacarik, Thai monks who sacrificed their time and voluntarily traveled to perform missionary work to hill tribe people in different provinces to respect Buddhism. Present himself as a Buddhist and send many children to ordinate and have the opportunity to study both the religious and ordinary education and traveled to spread Buddhism in the original hometown.

2. Missionary monks or Phra Dhammaduta is a monk, novices with sufficient knowledge of Buddhism can carry out the mission. Then sacrificed to meet with people in different places to find a way to persuade. People are interested in the values of morality and Buddhism.

3. General propagation of Buddhism consisted of preaching or lecturing on various occasions such as on Buddha's day or as received in various places on important days, broadcasting through various media such as radio, television, print, and other refers to the propagation that is coupled with other areas of development such as development or material aid, then convinced him to turn to Dhamma.

\section{Roles of monks in social work}

Social work duties of the monks arise from 3 aspects:

1. The life of a monk has to be related to the householder in 4 factors.

2. Social conditions and events call for change for the better.

3. Morality, compassion, and benevolence of monks who want to help others from suffering.

The role of monks in mental development, Buddhist principles clearly indicate that all Dharma has a heart as the head. Most noble accomplished by heart therefore, a well trained mind must be developed and there will be an outward development as well. The development of the mind according to the viewpoint of Buddhism is called prayer or meditation is to cause real enlightenment.

\section{The role of monks in cultural inheritance}

Culture is a way of life created by human beings for the benefit of living and passing on from ancestors to future generations. Culture is divided into 4 types as follows:

1. Art and culture which are archaeological sites, antiques and objects of art such as castle, royal palace, fortification temple, wall, and appearance that is not clearly shaped, such as a moat, an ancient road, and a covered mound, chedi, church, vihara, etc.

2. Art and Culture in painting, most of them are present in the temple.

3. Art and culture in the category of local arts and handicrafts.

4. Abstract art and culture such as ideas in attitudes, ideologies, traditions, beliefs and traditions.

The role of monks in promoting and preserving the environment with principles in Buddhism about nature, laws of nature, compliance with nature's regulations and the results obtained by following the laws of nature man is only part of nature. Therefore, there are many principles that show the need to conserve nature. In particular, the natural environment that humanity relies on for life also includes religious leadership roles that influence the villagers in rural and respectful urban communities. Accepting guidance or advice not only on matters related to religion, but also occupies an area in other dimensions as well, such as village development religious leaders are often informal leaders of the villagers. It has a high level of thought and spiritual influence on the villagers, so the monks should be a good role model. In morality to cultivate faith in the local people. They should develop themselves to be knowledgeable both in secular and moral ways in order to keep up with the changes of society which will affect the potential for mental development. The propagation of religious dhamma to Buddhists being a direct and indirect provider of teachings and religious principles, that is, being a trainee of Buddhists, indirectly is self-discipline which will build faith in the common people, and the provision of potential development training in spiritual development and religious principles for teachers and trainers to train youth in teaching youth morally, such as being a lecturer in educational institutions or organize projects and activities to bring Buddhists and 
youth to participate in religious training, which may be done by a group of people with a temple as the main theme of monks and media groups [6].

\section{Principles and methods of moral and ethical development according to the philosophy of sufficiency economy.}

Buddhism sees all human beings as "animal wonders" who have the potential to develop morally. Higher ethics respectively until the ultimate goal of life can be achieved the cultivating approach that Buddhism accepts both the influence of the environment and the use of wisdom to consider reason that is the only important element that makes learning and changing behavior of a person. These two elements must be complementary and coordinated well. Moral and ethical development goes well, and the two components are [7] :

1. Paratoghasa, outside environment refers to a good general social environment that contributes to the instillation of ethics in this place, focusing on the Kalyanamitra, that is, the person who gives good advice, such as parents, teachers, and the one who knows all means children with good Paratoghasa are more ethically advanced than children who live in harsh environments.

2. Yonisomanasikara, knowing how to use wisdom to rationalize, use thinking in the right way, known to think, that is, to distinguish and search for the root. According to the principle of the relationship of various factors, it is easy to understand, that is, think as a solution. In practice, creating moral ethics will depend partly on the environment, and create internal awareness, especially the thinking of another, part of the child. Teachers will help as Kalyanamitra, guiding them to use their thoughts in the correct way, thinking and reason, if there is no Kalyanamitra, Yonitsomanasikara is often difficult.

Monks are expected to play a role in moral and ethical development in accordance with the Sufficiency Economy Philosophy through various social institutions, where such roles are expected to have similarity. This is reason how the word role refers to the behaviors expected for those in different statuses to perform and the expected role in moral and ethical development is the role of monks where performing roles have limitations according to the principles of Buddhism. As a result, the roles that were expected were similar in the way that priests could perform properly which, according to the opinion of the monks, should play a role can be summarized as follows [8]:

1. Role in teaching morals, morals and ethics according to the sufficiency economy philosophy to build understanding of the concept and can be applied in both the temple sermons or being a teacher at an educational institution. This is a role that monks can perform through all forms of social institutions. In the form of a missionary whose missionary mission is a monk, novices with sufficient knowledge of Buddhism can proceed to disseminate. Then sacrificed to meet with the people in different places to be a way to persuade people to have an interest in moral values and Buddhism [9].

2. Role in leadership and role model in self-sufficiency life. Self-reliance is a role that monks can perform through all forms of social institutions, especially religious institutions which means self-possession according to the principle of discipline which can be a good role model for Buddhists. However, one desirable role of the monks is to be a good role model in morality to cultivate faith in the local people. This role is also in line with moral and ethical development by observing the model based on the Social Cognitive Theory. Most of the learning of people is through observation of the model which can be transmitted both thoughts and expressions at the same time.

3. Role in community collaboration educational institution government agencies to develop morals and ethics in instilling awareness among the people. Consciousness must be cultivated to have awareness (awareness), consciousness, collective action, network, co-ordination and cooperation.

4. Roles in organizing entertainment activities or recreational activities within the temple to promote moral and ethical youth, and role in arranging the landscape within the temple as a place to relax and appreciate nature. Since the Dhamma propagation can be coupled with other developments such as development or material aid, then convinced him to turn to Dhamma. In addition, the organized fair and entertainment activities persuade the youth to come to Paratoghasa or the external environment. This refers to a good general social environment that contributes to the instilling of ethics in this regard, focusing on the Kalyanamitra who gives good advice, are ready to make more ethical advances than children in harsh environments. Therefore, organizing a fair and entertainment activity is to instill the subject of morality to the youth whose youth are like pure whites. It is a soft wood that is easy to bend. Therefore, special attention should be given to the training and development of our youth as a child being a desirable youth, that is, a smart man with wisdom being a good person with virtue, happy in society.

Development of the role of the monks to be a lecturer in various knowledge. The principles are presented to the people, not necessarily just preaching must reach the public. There are very few monks that reach the people. If the monks are skilled and loving. There are various institutions promoting in all aspects. There is encouragement for the little ones to gain power for the masses. We have to create faith. We will gain cooperation and develop in a process and can integrate as required.

\section{Conclusion}

The role of the monks to develop morality and ethics according to the philosophy of sufficiency economy to be successful depends on the monks must have good faith first. That is, first of all, if we do not have faith to propose however villagers would not trust neither believe nor will cooperate. Therefore, the first thing to be successful is that the monks have to have good practice and good precepts to be able to lead for the success, namely the monks in the temple whether it is a leader, a leader of sub-district, a leader of district, and the leader of province, abbot of every temple, general monks and priests should have determination in teaching at the monk himself. If we stay, be a teacher and stayed for him to see what the characteristics of a monk, how to do and promote good morals and ethics like that. If the monks have shown good role of model, they can be followed, and they are considered the best 
teachers. Monks have to understand their roles first and it is also important to education as monks are a symbol of education. If monks understand their role first and develop their potential for moral development, it is an abstract matter that should be accomplished. You must know the potential of people who have to develop morally and to understand our role.

\section{References}

[1] Department of Religious Affairs, Ministry of Culture And the researcher Suan Dusit poll Suan Dusit Rajabhat University, Project to study the role of monks and moral and ethical development according to the Sufficiency Economy Philosophy, Bangkok: Ministry of Culture, 2007.

[2] Phra Dharmapitaka, (Prayut Payutto), SustainableDevelopment, Bangkok: Saha Thamik Company, 2539.

[3] N. Thongpakdee, Philosophy of Sufficiency Economy: Applying the Philosophy of Sufficiency Economy and Development Management, Bangkok: National Institute of Development Administration, 1997.

[4] Phramaha Krisada Nantaphet, The attitude of the monks on the role of social development. Master's Thesis, Faculty of Social Development National Institute of Development Administration, 1997.

[5] His Majesty King Muni, (P.A.Payutto), Sangha Education: Problems Waiting for a Solution, Bangkok: Ruen Kaew Publication, 2539.

[6] Y. Saengsoda. The role of monks in solving Thai social problems. Study the case of Sajja Somsap Group, Nonthaburi Master of Arts Mahidol University, 2544.

[7] S. Suksaran, Development of Buddhism A case study for the developer monks. Bangkok: Beautiful type to print, 2532.

[8] N. Sanguan, Principles of anthropology, Bangkok: Print at Chao Phraya Printing, 2532.

[9] Thidnakhammanee, Development of morality, ethics and values: from theory to practice. Bangkok: The Social Work
Council of Thailand, Under royal Patronage, 1998 